\title{
Changes of Learning and Memory Ability in fos-GFP Transgenic Mice
}

\author{
Chen $\mathbf{W}^{1}$, Cao Hais ${ }^{1}$, Sun Xiao $\mathbf{M}^{1}$
}

${ }^{1}$ Laboratory of Physiology, College of Basic Medicine, Qingdao University, Qingdao City, Shandong Province, China, 266000

\begin{abstract}
Objective To study the changes of learning and memory ability in fos-GFP transgenic mice. Methods The mice in the fos-GFP group and the control were tested by using overhead cross maze,open field,and Morris Water Maze ${ }^{[1]}$. The spontaneous activity,anxiety state,the ability of learning and memory were tested as well. Results The differences between fos-GFP mice and the control were not significant in terms of distance of motion within the field,velocity,duration of stay at the marginal zone,and duration of open arm in the maze $(p>0.05)$. The difference between the mice in the two groups was not significant with regard to latency of finding the flat at each time point $(p>0.05)$, and the percentage of duration in target quadrant in Morris Water Maze $(p>0.05)$, and similar freezing time in contextual fear conditioning test $(\mathrm{p}>0.05)$. The fos-GFP mice showed higher freezing level than normal controls in no-exposed fear conditioning $(\mathrm{t}=9.48, \mathrm{P}<0.001)$. Conclusion The ability of hippocampus-dependent associative learning and memory in fos-GFP transgenic mice was somewhat improved.
\end{abstract}

Keywords: fos-GFP Fused Protein, Learning, Memory, Neurobehavioral Manifestations, Mice

\section{Introduction}

Immediate early genes (IEGs) are a group of genes that express fastest in cells after receiving various external stimuli ${ }^{[2]}$. IEGs are not only involved in the normal growth and differentiation of cells, but also in the process of intracellular information transmission and energy metabolism.The activation of IEGs usually occurs before cells synthesize any new protein, so it is also called the entrance of cytogenetic response $^{[2]}$. At present, there are 40 kinds of IEGs discovered, among which c-fos is one of the earliest and clearest IEGs ${ }^{[3]}$.Studies have shown that IEGs such as c-fos, zif268, Arc and their protein products are involved in the formation of learning and memory and long-term potentiation.It is worth noting that the up-regulation of IEGs such as c-fos can reliably reflect the increase of neuronal electrical activity ${ }^{[4]}$, so it is widely used as a marker of neuronal activity. Fo-GFP transgenic mice use FOS promoter to activate the expression of fos-GFP fusion gene. It is the first transgenic mice that use GFP expression to reflect IEG expression, i.e. neuronal activity. With the help of fluorescence microscopy and fos-GFP transgenic mice, we can clearly observe the changes of neuronal activity in the nerve loop after stimulation, thus providing a powerful experimental tool for exploring the mechanism of nerve activity in the loop.However, because fos-GFP transgenic mice carry multiple copies of fos-GFP gene, Fos protein is also overexpressed while overexpressing GFP.Whether overexpression of Fos proteins affects animal behaviour, such as learning and memory, remains unclear. This study investigated the changes of learning and memory abilities of fos-GFP transgenic mice by means of various behavioral testing methods related to learning and memory, and provided theoretical and experimental basis for the follow-up related research.

\section{Materials and methods \\ 1.1 Experimental animal}

Fos-GFP transgenic mice were donated by Professor Alison Barth of the United States and crossed with wild-type C57B16J mice purchased by Jackson Company of the United States. During the feeding process, the mice were fed and drank freely. The animal room kept constant temperature and humidity. The circadian rhythm was 12 hours.Ten fos-GFP transgenic mice of 3-6 months old and 28-38g body weight and 10 wild-type adult mice (control group) born in the same litter were selected for behavioral test after genotype identification ${ }^{[5]}$.

\subsection{Experimental method}

The spontaneous activity, anxiety and learning and memory abilities of fos-GFP transgenic mice were tested by a variety of behavioral testing methods. Mainly includes: elevated cross maze, open field experiment, water maze test, conditional scene fear memory test ${ }^{[6]}$.The equipment used for cross labyrinth, open field experiment and water labyrinth test is self-made in laboratory. The monitoring system and analysis software are purchased from Noldus Company. The Scene Conditional Fear Memory Testing System and Analysis Software were purchased from MEDAssociates Inc.

\subsubsection{Elevated Plus Maze}

Our maze is made of stainless steel, which is painted matte black, and consists of four arms(two open 
without walls and two enclosed by $15.25 \mathrm{~cm}$ high walls) $30 \mathrm{~cm}$ long and $5 \mathrm{~cm}$ wide ${ }^{[7]}$. Each arm of the maze is attached to sturdy metal legs such that it is elevated $40 \mathrm{~cm}$ off of the table it is on. The maze was purchased from Columbus Instruments. In comparison to the rat elevated plus maze that we use, the mouse maze is smaller and is readily moved as necessary ${ }^{[8]}$. As such, a mouse elevated plus maze constructed of stainless steel without a movable base is used in our laboratory ${ }^{[9]}$. We have found similar patterns of behavior when we have used mouse elevated plus mazes from other commercial vendors and with slightly different construction (i.e., closed-arms made of clear rounded Plexiglas) and when the maze was situated on the floor, instead of a table. The elevated plus maze is a widely used behavioral assay for anxiety behavior of rodents. It is easy to use, can be fully automated and valid results can be obtained in a short, 5-min testing period. The patterns of results obtained using this task are replicable across other species, anxiety/affective behavior measures, studies and laboratories ${ }^{[10]}$.

\subsubsection{Open field test}

The open field test is used to analyze locomotion, anxiety and stereotypical behaviors such as grooming and rearing in rodents.For mice, the test area normally consists of a $42 \times 42 \times 42 \mathrm{~cm}$ polyvinyl chloride (PVC) box and a camera is used to monitor movement into and around the central and peripheral areas of the box ${ }^{[11]}$. Changes in locomotion can be indicative of altered neurological processes and may therefore reflect abnormal brain function.this test may be used to assess general health and wellbeing of an animal. Animals that are not healthy tend to move less within the area.Mice that are stressed show less activity in the open field and increased stereotypical behavior.Such behaviors include those that are repetitive, invariant and seemingly without purpose $^{[12]}$. Mice that prefer staying close to the walls and travel more in the periphery can be described as showing thigmotaxis (movement towards a solid object), which is pronounced in mice showing signs of anxiety-like behavior. Mice with lower anxiety tend to spend more time in the central, open area of the box ${ }^{[13]}$.

\subsubsection{Water maze}

The water maze consisted of a circular galvanized steel pool $117 \mathrm{~cm}$ in diameter and $58 \mathrm{~cm}$ deep. A movable escape platform constructed of a Plexiglas base column having a height of $43 \mathrm{~cm}$ and topped by a round platform $15 \mathrm{~cm}$ in diameter, was placed in one quadrant of the pool and was maintained there throughout acquisition of the task $\mathrm{k}^{[14]}$. The water was filled to a height of $47 \mathrm{~cm}$ and maintained at $26+1^{\circ}$ $\mathrm{C}$, and rendered opaque with nontoxic, water-soluble white paint. Water level was maintained at $2 \mathrm{~cm}$ above the platform's surface ${ }^{[15]}$. There were many prominent visual cues that remained constantly positioned around the testing room throughout the study, to serve as distal spatial cues to the location of the platform ${ }^{[16]}$. No local cues were present within the pool.A stopwatch was used to measure latency to reach the platform during acquisition trials ${ }^{[17]}$. A video camera was mounted on the ceiling to record the rats' swim patterns during the probe trials and individuals blinded to group assignment scored the videos to obtain the retention data ${ }^{[18]}$.

\subsubsection{Fear conditon test}

Conditional Scene Fear Memory Test mice were placed in the test box. After 2 minutes, they were given plantar electric shock $(0.75 \mathrm{~mA}, 2 \mathrm{~s})$. After the shock, the mice were allowed to stay in the test box for 3 minutes and then put back into the cage. After 24 hours, mice were placed in the same test box to test their fear response to the scene. If the mice had a fear memory of the scene, the spontaneous activity decreased or stopped ${ }^{[19]}$.

\subsection{Statistical Analysis}

The experimental data were analyzed by GraphPad Prism 4.0 software. Group $\mathrm{t}$ test was used for comparison between groups, $\mathrm{P}<0.05$ was significant difference.

\section{Results}

2.1 Comparison of spontaneous activity and anxiety status between two groups of mice

The open arm exploring time of the transgenic mice and the control mice in the cross maze experiment was $(23.56+6.24) \mathrm{s}$ and $(17.56+3.33) \mathrm{s}$, respectively. There was no significant difference between the two groups $(\mathrm{P}>0.05)$. There was no significant difference between fos-GFP transgenic mice and control mice in the distance, speed and time spent at the edge of the open field. $(\mathrm{P}>0.05)$

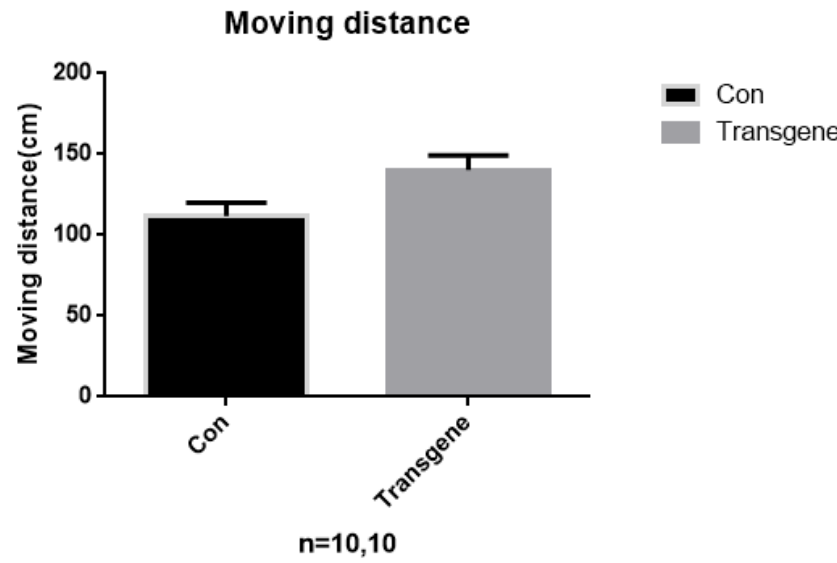



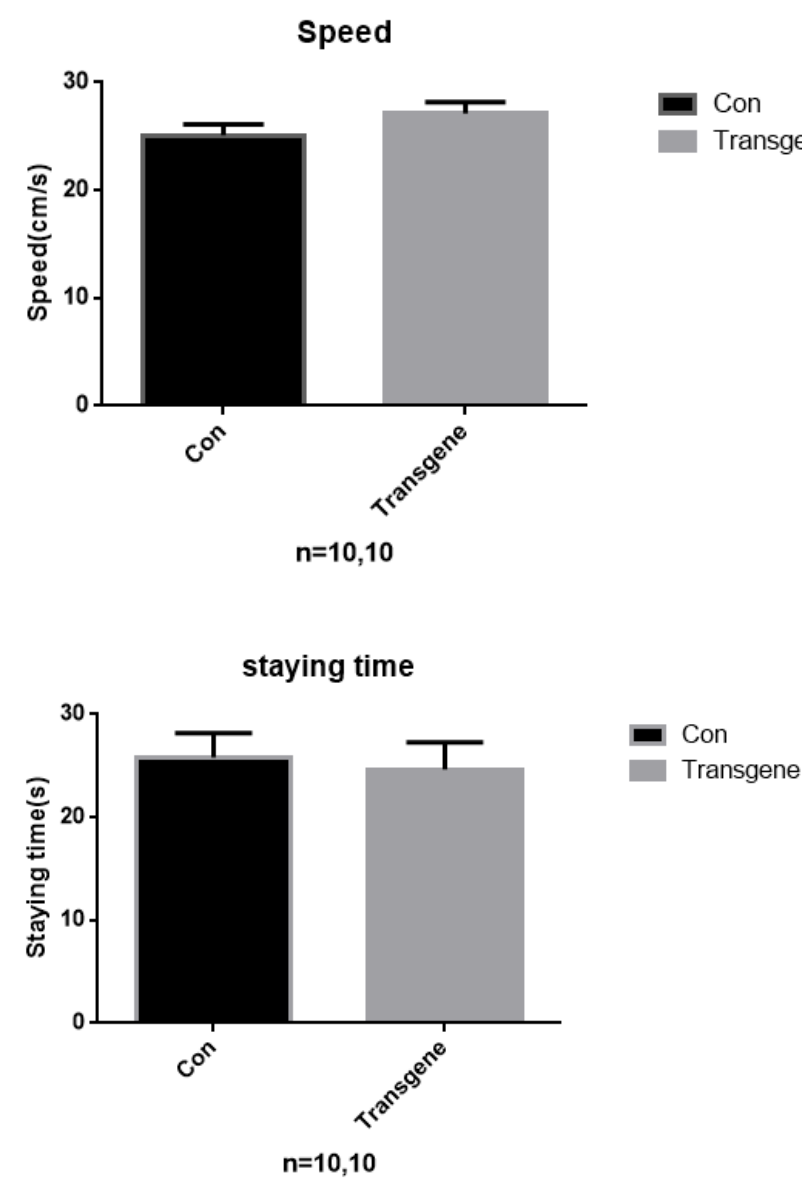

2.2 Comparison of spatial learning and memory ability between two groups of mice

There was no significant difference in latency of finding platform between the two groups at different time points during water maze training $(\mathrm{P}>$ 0.05 ,Figure 1$)$. After 10 days of training, there was no significant difference in the percentage of water maze test time in each quadrant between the two groups $(\mathrm{P}>0.05$,Figure2).

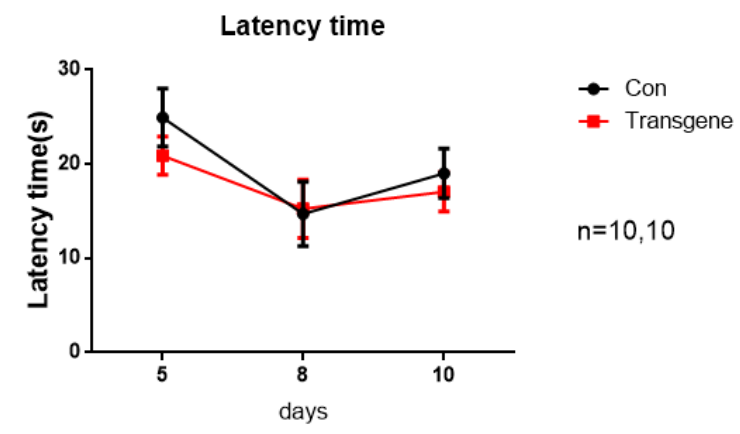

Figure1

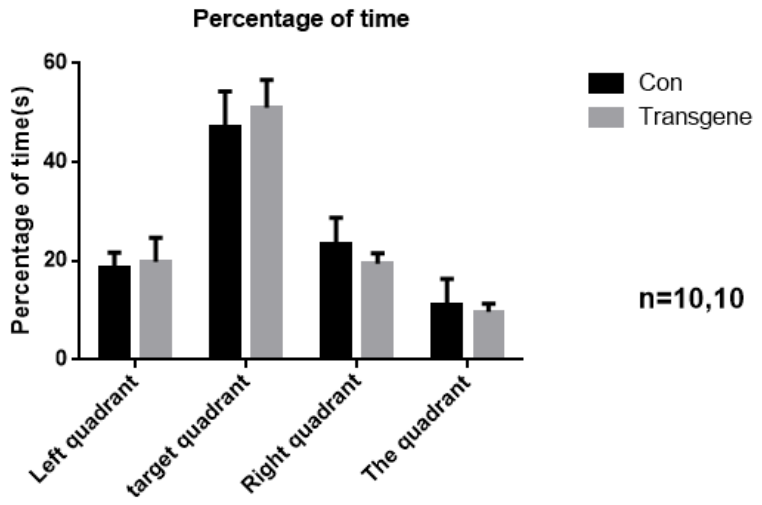

Figure2

\subsection{Comparison of Scene Fear Memory Ability of Two Groups of Mice after Early Contact with Scene \\ The stiffness time of fos-GFP transgenic mice in conditional fear test was $(33.01 \pm 4.08 \%)$ in the absence of specific scenarios and $(14.34 \pm 4.02 \%)$ in the control group. There was a significant difference between the two groups $(\mathrm{t}=9.48, \mathrm{P}<0.001)$.}

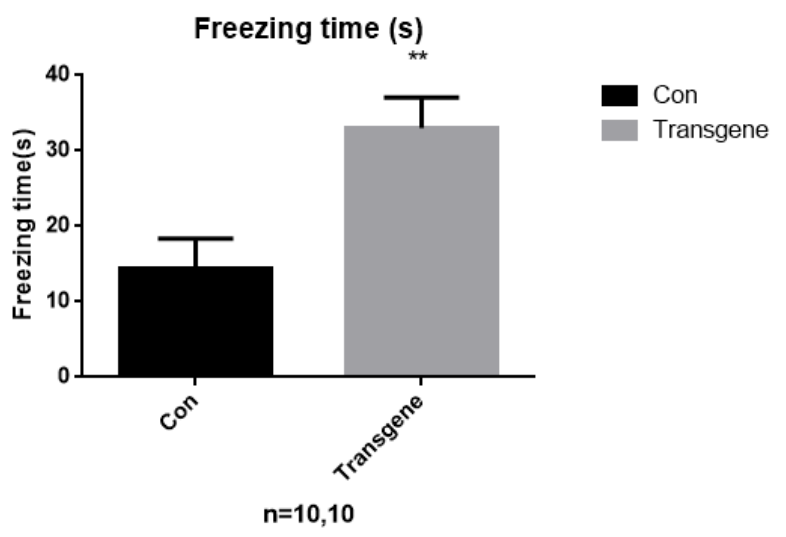

3. Discussion

The results of this study showed that the mice in the control group showed a loss of scene fear memory when they did not contact in advance, that is, no fear reaction when they were in the same scene again, which was consistent with the results of literature, and the early contact of scene could correct the loss of scene fear memory ${ }^{[20]}$.The results of this study showed that fos-GFP transgenic mice received immediate plantar shock $(<5 \mathrm{~s})$ in the test scenario, which resulted in long-term fear of the scenario, and their fear memory was similar to that of the scenario pre-exposure group.The results showed that fos-GFP transgenic mice acquired scene memory, scene and plantar shock combined memory faster than control mice. It also showed that over-expression of fos-GFP fusion protein could correct the lack of scene fear memory without prior contact.Because the spontaneous activity and anxiety state of fos-GFP 
transgenic mice were not significantly different from that of normal mice ${ }^{[21]}$, and the learning and memory ability of spatial and conditioned scene fear was not significantly different from that of normal control mice, which indicated that the enhancement of hippocampus-dependent learning and memory ability of fos-GFP transgenic mice was related to their spontaneous activity, the change of anxiety state and other non-specific factors.

Fos-GFP transgenic mice were the first transgenic mice to use the expression of green fluorescent protein to reflect IEG expression, i.e. neuronal activity. With the help of fluorescence microscopy, the activity changes of neurons in the nerve circuitry after stimulation can be clearly observed in the transgenic mice ${ }^{[22]}$. More and more researchers use fos-GFP mice as a genetic tool to identify and analyze the activated neurons and their plasticity changes in the whole behavioral experiment (learning and memory).Fo-GFP mice can display excitability changes of cells after in vivo stimulation, thus exploring the spirit.Activity-related loop mechanisms provide new tools. However, because fos-GFP mice carry multiple copies of fos-GFP gene, Fos protein is also overexpressed while overexpressing GFP.When the electrical activity of $2 / 3$ cortical cells of fos-GFP mice was recorded on brain slices in vitro, it was found that when the cell membrane potential was maintained at $-50 \mathrm{mV}$, the firing frequency of GFP-labeled neurons (i.e. neurons expressing large amounts of Fos protein) was twice as high as that of non-labeled neurons ${ }^{[23]}$. However, the intrinsic excitability of GFP-labeled neurons was lower than that of non-labeled neurons. At the same time, the frequency of spontaneous EPSPs of GFP-labeled neurons was higher than that of non-labeled neurons, but there was no significant difference in micro-EPSPs. These findings suggest that GFP-labeled neurons may receive more excitatory inputs than non-labeled neurons. Whether these changes in electrophysiological properties caused by overexpression of Fos protein will affect the overall behaviour of animals, such as learning and memory, remains unclear ${ }^{[24]}$. Through detailed behavioral observation and analysis, the results show that fos-GFP transgenic mice have improved their combined learning and memory abilities, which provides theoretical and experimental basis for subsequent research on the use of this transgenic mice. However, the changes of learning and memory abilities and molecular mechanisms of fos-GFP transgenic mice need to be further studied.

\section{Acknowledgement}

The author is very grateful to all my classmates and teachers in the Department of Physiology, Basic Medical College of Qingdao University for their hard work.

\section{References}

1. A O C, SMEDBERG D L, SHIN A L, et al. Familial risk for psychiatric disorders in military veterans who have post-traumatic stress disorder with psychosis: a retrospective electronic record review [J]. Psychiatric genetics, 2018, 28(2): 24-30.

2. ALWAY Y, GOULD K R, MCKAY A, et al. The Evolution of Post-Traumatic Stress Disorder following Moderate-to-Severe Traumatic Brain Injury [J]. Journal of neurotrauma, 2016, 33(9): 825-31.

3. ALZOUBI $\mathrm{K} H$, AL SUBEH $Z$ Y, KHABOUR $O \quad F$. Evaluating the protective effect of etazolate on memory impairment, anxiety- and depression-like behaviors induced by post traumatic stress disorder $[\mathrm{J}]$. Brain research bulletin, 2017, 135(185-92.

4. ANJANA B, AMTESHWAR SINGH J. An Integrative Review on Role and Mechanisms of Ghrelin in Stress, Anxiety and Depression [J]. Current Drug Targets, 2016, 17(5): 495-507.

5. ATLI A, BULUT M, BEZ Y, et al. Altered lipid peroxidation markers are related to post-traumatic stress disorder (PTSD) and not trauma itself in earthquake survivors [J]. European archives of psychiatry and clinical neuroscience, 2016 266(4): 329-36.

6. BOKS M P, RUTTEN B P, GEUZE E, et al. SKA2 Methylation is Involved in Cortisol Stress Reactivity and Predicts the Development of Post-Traumatic Stress Disorder (PTSD) After Military Deployment [J]. Neuropsychopharmacology : official publication of the American College of Neuropsychopharmacology, 2016, 41(5): 1350-6.

7. CORDERO M I, MOSER D A, MANINI A, et al. Effects of interpersonal violence-related post-traumatic stress disorder (PTSD) on mother and child diurnal cortisol rhythm and cortisol reactivity to a laboratory stressor involving separation [J]. Hormones and behavior, 2017, 90(15-24.

8. DIGANGI J A, GORKA S, AFSHAR K, et al. Differential impact of post-deployment stress and PTSD on neural reactivity to emotional stimuli in Iraq and Afghanistan veterans [J]. Journal of psychiatric research, 2018, 96(9-14.

9. EBENEZER P J, WILSON C B, WILSON L D, et al. The Anti-Inflammatory Effects of Blueberries in an Animal Model of Post-Traumatic Stress Disorder (PTSD) [J]. PloS one, 2016, 11(9): e0160923.

10. FERNANDEZ-MORIANO C, GONZALEZ-BURGOS E, IGLESIAS I, et al. Evaluation of the adaptogenic potential exerted by ginsenosides $\mathrm{Rb} 1$ and $\operatorname{Rg} 1$ against oxidative stress-mediated neurotoxicity in an in vitro neuronal model [J]. PloS one, 2017, 12(8): e0182933.

11. FISHBAIN D A, PULIKAL A, LEWIS J E, et al. Chronic Pain Types Differ in Their Reported Prevalence of Post -Traumatic Stress Disorder (PTSD) and There Is Consistent Evidence That Chronic Pain Is Associated with PTSD: An Evidence-Based Structured Systematic Review [J]. Pain medicine (Malden, Mass), 2017, 18(4): 711-35.

12. GILPIN N W, WEINER J L. Neurobiology of comorbid post-traumatic stress disorder and alcohol-use disorder [J]. Genes, brain, and behavior, 2017, 16(1): 15-43.

13. GUEST R, TRAN Y, GOPINATH B, et al. Prevalence and psychometric screening for the detection of major depressive disorder and post-traumatic stress disorder in adults injured in a motor vehicle crash who are engaged in compensation [J]. BMC psychology, 2018, 6(1): 4.

14. HASHTJINI M M, JAHROMI G P, SADR S S, et al. Deep brain stimulation in a rat model of post-traumatic stress disorder modifies forebrain neuronal activity and serum corticosterone [J]. Cognitive behaviour therapy, 2018, 21(4): 370-5.

15. HE Y Q, LANG X Q, LIN L, et al. P2X3 receptor-mediated visceral hyperalgesia and neuronal sensitization following exposure to PTSD-like stress in the dorsal root ganglia of rats [J]. 2017, 29(3)

16. LISIESKI M J, PERRINE $\mathrm{S}$ A. Binge-pattern cocaine administration causes long-lasting behavioral hyperarousal 
but does not enhance vulnerability to single prolonged stress in rats [J]. Journal of molecular neuroscience : MN, 2017, 257(95-101.

17. HEIN I, DJELANTIK A, SMID G E, et al. Do prolonged grief disorder symptoms predict post-traumatic stress disorder symptoms following bereavement? A cross-lagged analysis [J]. European journal of pediatrics, 2018, 80(65-71.

18. HORLINGS A. Psychiatric screening and interventions for minor refugees in Europe: an overview of approaches and tools [J]. Human brain mapping, 2018, 177(2): 163-9.

19. JI L L, PENG J B, FU C H, et al. Sigma-1 receptor activation ameliorates anxiety-like behavior through NR2A-CREB-BDNF signaling pathway in a rat model submitted to single-prolonged stress [J]. Molecular medicine reports, 2017, 16(4): 4987-93.

20. JIANG J H, PENG Y L, ZHANG P J, et al. The ventromedial hypothalamic nucleus plays an important role in anxiolytic-like effect of neuropeptide $S[\mathrm{~J}]$. Neuropeptides,
2018, 67(36-44.

21. KELLER S M, SCHREIBER W B, STAIB J M, et al. Sex differences in the single prolonged stress model [J]. Behavioural brain research, 2015, 286(29-32.

22. LAUKOVA M, ALALUF L G, SEROVA L I, et al. Early intervention with intranasal NPY prevents single prolonged stress-triggered impairments in hypothalamus and ventral hippocampus in male rats [J]. Endocrinology, 2014, 155(10): 3920-33.

23. LEVONE B R, CRYAN J F, O'LEARY O F. Role of adult hippocampal neurogenesis in stress resilience [J]. Neurobiology of stress, 2015, 1(147-55.

24. LIM S I, SONG K H, YOO C H, et al. Decreased Glutamatergic Activity in the Frontal Cortex of Single Prolonged Stress Model: In vivo and Ex Vivo Proton MR Spectroscopy $[\mathrm{J}]$. Neurochemical research, 2017, 42(8): 2218-29. 